\title{
Aspectos biológicos e atividade tumorigênica da família proto- oncogênica Ras
}

\section{Biological aspects and tumorigenic activity of the Ras proto- oncogenic family}

\author{
Juliano André Boquett ${ }^{1}$; Reginaldo Justino Ferreira ${ }^{2}$
}

\begin{abstract}
Resumo
Os proto-oncogenes desempenham importante papel na regulação do ciclo celular, e são críticos à tumorigênese. Nessa categoria se encontra a família RAS, que, devido ao elevado potencial transformante dos genes que a compõem, é uma das mais bem descritas e estudadas. É formada pelos genes H-, K- e N-RAS, que codificam proteínas altamente relacionadas expressas em vários tipos de células, denominadas p21. Estas atuam na transdução de sinal da membrana ao núcleo, estão envolvidas no controle da proliferação, diferenciação e morte celular e são reguladas pela interação com GDP (inativa) e GTP (ativa). As proteínas p21 diferem em apenas $10-15 \%$ da sua estrutura primária, na porção C-terminal, denominada região hipervariante. Quando na forma oncogênica, permanecem ativas, e conferem estímulo contínuo à proliferação celular. Dentre os genes RAS, K-RAS tem sido o mais estudado, por apresentar mutações mais freqüentes e presentes em tumores mais agressivos, e implicar em menor sobrevida aos pacientes. Pelo importante papel já demonstrado na formação de tumores e relativa carência de bibliografia em língua portuguesa acerca dessa família gênica, apresentamos neste trabalho uma revisão sistematizada e atualizada sobre os proto-oncogenes RAS.
\end{abstract}

Palavras-chave: K-RAS, p21. Oncogene. Transdução de sinal.

\begin{abstract}
Proto-oncogenes play an important role in the regulation of the cellular cycle, being critical to the tumorigenesis. In this category we can find the RAS family. Due to the high transformation potential of these genes, this family is the best described and most studied one. It is formed by the H-, K- and the N-RAS genes, that codify highly related proteins expressed in several types of cells, denominated $\mathrm{p} 21$.These proteins act in the sign transduction from the membrane to the nucleus, as well as in the control of proliferation, differentiation and cellular death, and they are regulated by the interaction with GDP (inactive) and GTP (active). These proteins show variation in only $10-15 \%$ of the primary structure, in the $\mathrm{C}$-terminal portion denominated hyper-variant region. When in the oncogenic form, the 21 proteins remain active, providing continuous stimuli to the cellular proliferation. Among the RAS genes, K-RAS ones have been the most studied for presenting more frequent mutations and for being present in more aggressive tumors, implying the patients' shorter survival time. Due to these facts and relative bibliography lack in the Portuguese language on this family, we presented in this work a systematized and updated review on the RAS genes.
\end{abstract}

Key-words: K-RAS, p21. Signal transduction. Oncogene.

\footnotetext{
1 Biólogo, discente do Programa de Pós-Graduação em Genética e Biologia Molecular da UFRGS, Av. Bento Gonçalves, 9500, Agronomia, 91501-970, Porto Alegre, RS. E-mail: julianob9@hotmail.com

2 Biólogo, docente da Universidade Tecnológica Federal do Paraná - UTFPR campus Toledo, Av. XV de Novembro, 2191, Jardim La Salle, 85902-040, Toledo, PR. E-mail: reginaldojf@utfpr.edu.br
} 


\section{Introdução}

Entre os inúmeros genes humanos já identificados, um grupo tem atraído especial atenção nas últimas décadas, devido ao potencial demonstrado na indução da formação de neoplasias: os oncogenes. Estes consistem em formas mutadas de genes que codificam produtos ligados direta ou indiretamente à promoção da proliferação celular, e são denominados proto-oncogenes. Os protooncogenes são considerados críticos ao processo de carcinogênese, tornando seu estudo fundamental para a compreensão dos eventos celulares que levam ao desenvolvimento de neoplasias.

Mais de 50 proto-oncogenes humanos - e seus respectivos oncogenes - já foram identificados, e poucos deles são herdados (síndromes de cânceres hereditários) (NUSSBAUM; McINNES; WILLARD, 2008). A ativação, denominação da transformação de um proto-oncogene em oncogene, ocorre como resultado de: a) mutação de ponto; b) amplificação gênica; e/ou c) rearranjo cromossômico. Como a presença de um único alelo mutante é o suficiente para mudar o fenótipo celular, consideram-se os oncogenes dominantes no nível celular (NUSSBAUM; McINNES; WILLARD, 2003).

De acordo com as propriedades funcionais e bioquímicas dos produtos protéicos, os protooncogenes são classificados em cinco grupos: (1) fatores de crescimento, (2) receptores de fatores de crescimento, (3) sinais de transdução, (4) fatores de transcrição, e (5) reguladores da morte celular programada e outros. Muitos proto-oncogenes são membros das vias dos sinais de transdução, que consistem de dois grupos principais: (1) nãoreceptores de proteínas quinases e (2) proteínas ligantes de guanosina-trifosfato $(\mathrm{G})$. Proteínas $\mathrm{G}$ são classificadas em monoméricas e heterotriméricas. As proteínas monoméricas ligantes de GTP são membros da importante família proto-oncogênica RAS (BAST et al., 2000).

Os proto-oncogenes RAS compõem uma família de genes estruturalmente relacionados e expressos em vários tipos de células normais: H-RAS, N-RAS e K-RAS. Elas codificam uma pequena família de proteínas com alto poder transformante (ELLIS; CLARK, 2000).

Entre os membros da família RAS, o gene K-RAS tem sido o mais estudado, pois apresenta mutações mais freqüentes e os tumores que as contém são mais agressivos, e isso implica em menor sobrevida aos pacientes (DENHARDT, 1996; PACHECO; PASCHOAL; CARVALHO， 2002; GOLBERT et al., 2003). O gene K-RAS codifica um transdutor de sinal extracelular, a proteína k-ras, que transmite informações da membrana ao núcleo e é um elemento-chave na regulação da proliferação e diferenciação celular (ELLIS; CLARK, 2000; OLIVEIRA; CURY, 2002). Na forma transformada (oncogênica), seu produto promove sinalização prolongada e desequilibrada da membrana ao núcleo, e contribui para formação de um fenótipo neoplásico maligno.

Devido à sua importância no estudo da formação e progressão de neoplasias e também pela relativa carência de bibliografia em língua portuguesa acerca dessa família proto-oncogênica, apresentamos neste trabalho uma revisão sistematizada e atualizada sobre os genes RAS.

\section{Proto-Oncogenes Ras}

Aspectos moleculares

Atualmente mais de 100 proteínas G monoméricas já foram identificadas em eucariotos, com massa molecular variando entre 20 e $40 \mathrm{kDa}$. Essa grande família de proteínas compreende, ao menos, 5 subfamílias classificadas estruturalmente em: (1) ras, (2) rho, (3) rab, (4) sarl/arf, e (5) ran. Primariamente, os membros da família ras estão envolvidos na regulação da expressão gênica (POCHYNYUK; STOCKAND; STARUSCHENCO, 2007).

Os genes H-RAS, N-RAS e K-RAS apresentam 
loci citogenéticos 11p15.5, 1p13.2 e 12p12.1, respectivamente (DEMIRAG; ATALAY; CRISS, 2000) e codificam proteínas altamente relacionadas, convencionalmente denominadas h-, n- e k-ras. Estas, com peso de $21 \mathrm{kDa}$, podem ser denominadas também de p21. Proteínas p21 são produzidas na forma precursora citoplasmática e são encontradas ancoradas à superfície interna da membrana plasmática por lipídeos, adicionados por modificação pós-traducional (REUTER; MORGAN; BERGMANN, 2000; PACHECO; PASCHOAL; CARVALHO, 2002; GOLBERT et al., 2003).

A proteína k-ras possui duas isoformas. A principal, com 189 resíduos de aminoácidos, é denominada k-ras4B e apresenta menor estabilidade em relação às proteínas h-, n- e k-ras4A. A forma secundária, k-ras4A, exibe discreta atividade transformante e contém 188 aminoácidos. Mutações em K-RAS expressam potencialmente ambas as isoformas, simultaneamente (ELLIS; CLARK, 2000).

As diferenças funcionais entre as proteínas ras podem estar refletidas em sua estrutura primária. Dos mais de 180 resíduos que as compõem, os primeiros

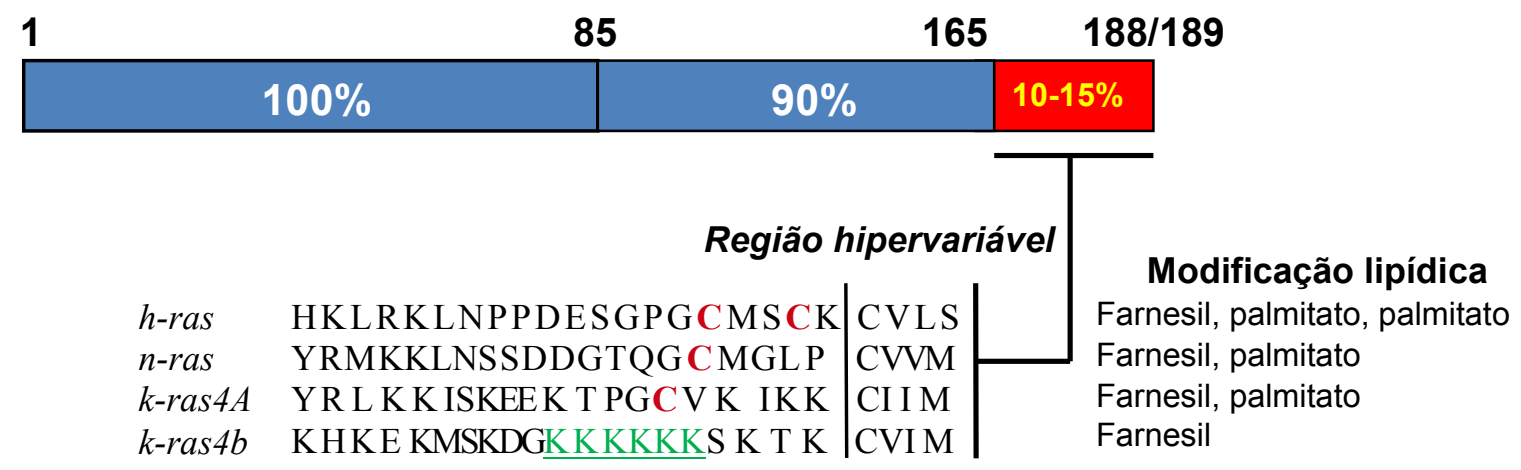

Figura 1. Proteínas ras: detalhe da região hipervariável (165-188/189). Resíduos de cisteína onde ocorre palmitolação em h-, n- e k-ras4A (em vermelho); domínios polibásicos de lisina (K) em k-ras4B (em verde, grifado).

Fonte: Adaptado de Prior e Hancock (2001).
120 são praticamente os mesmos. As proteínas he k-ras são idênticas até o resíduo 97, com apenas duas diferenças até o resíduo 120. Contudo, a porção C-terminal dessas proteínas apresenta grande variação, com índice de conservação de apenas 10 a $15 \%$, atribuindo-se à denominação de domínio hipervariante entre os resíduos 165 e 188/9 (Figura 1) (PRIOR; HANCOCK, 2001). Essa região é pouco caracterizada estruturalmente, porém se acredita que seja altamente flexível, e serve para evidenciar diferenças entre as proteínas ras (ELLIS; CLARK, 2000; PRIOR; HANCOCK, 2001).

Diferenças bioquímicas já foram bem caracterizadas no domínio hipervariante das proteínas ras. A associação estável destas com a membrana plasmática é dependente de modificação lipídica farnesil na porção C-terminal. As proteínas h-, n- e k-ras4A recebem uma modificação adicional, fundamental à sua atividade: a adição de um grupo palmitato aos resíduos de cisteína, também na porção C-terminal. Em h-ras, são adicionados dois grupos. Por não possuir resíduos de cisteína na porção C-terminal, a proteína k-ras4B não apresenta este tipo de modificação o que é, aparentemente, substituído por um alongamento de resíduos lisina (175-180) (ELLIS; CLARK, 2000; PRIOR; 
Vários trabalhos demonstraram através de imunocitoquímica de GFP(Green fluorescent protein), que a localização da proteína k-ras na membrana difere da localização de $\mathrm{h}$ - e n-ras, e isso sugere a existência de diferenças biológicas importantes entre as isoformas ras em suas vias de sinalização (ELLIS; CLARK, 2000), resultantes de divergências na região hipervariante (PRIOR; HANCOCK, 2001).

O transporte das proteínas h-ras e n-ras do retículo endoplasmático até a membrana plasmática obedece à via secretora clássica através do complexo de Golgi. Em contraste, a proteína k-ras (isoforma 4B) faz uma via alternativa, aparentemente sem trafegar pelo complexo de Golgi. Esta via "Golgi-independente" não está caracterizada e seu estudo ainda consiste um desafio (PRIOR; HANCOCK, 2001; EHRHARDT et al., 2002).

As proteínas h-ras são ancoradas a lipídeos na membrana plasmática, enquanto k-ras se dispersa ao longo da membrana plasmática (PRIOR; HANCOCK, 2001; KIM; LINDSTROM; GOULD, 2002), e, provavelmente, é influenciada por microtúbulos (ELLIS; CLARK, 2000). Esta localização é determinante da atividade oncogênica (ELLIS; CLARK, 2000).

Em alguns tipos celulares, o proto-oncogene K-RAS pode ser expresso sozinho, enquanto $\mathrm{H}$ - e N-RAS são sempre expressos na presença de outra isoforma, tornando as células mais sensíveis ao nocaute de K-RAS. Isso sugere que K-RAS tem função única, diferente de H- e N-RAS, que seriam funcionalmente redundantes (OLSON; MARAIS, 2000). Segundo Fotiadou et al. (2007), N-RAS regula a adesão celular, enquanto K-RAS coordena sua motilidade.

\section{Atividade biológica}

As proteínas ras agem praticamente da mesma forma em diferentes tipos de células normais. Trafegam pelo citoplasma e atuam na transdução de sinal do meio extracelular (PACHECO;
PASCHOAL; CARVALHO, 2002; DUURSMA; AGAMI, 2003; ALBERTS et al., 2004), controlando vias de sinalização reguladoras da proliferação celular normal. Recentemente, tem sido reportada também sua participação em processos neuronais, como aprendizado, memória e plasticidade sináptica (DENAYER; RAVEL; LEGIUS, 2008). As formas selvagens existem em baixa concentração na maioria das células normais e tem características cinéticas semelhantes às da subunidade alfa normal da proteína G (DEMIRAG; ATALAY; CRISS, 2000).

Proteínas ras exibem dois estados distintos: ligadas a GTP (ativas) ou a GDP (inativas), e são apenas a forma ligada à GTP capaz de mediar a resposta à proliferação celular. Proteínas ras são GTPases com grande atividade enzimática, que é reduzida nas proteínas codificadas pelos alelos mutantes. Sua mudança de estado quanto à ligação à GTP ou GDP ocorre por ação intrínseca (KUBRUSLY et al., 2002; MALUMBRES; BARBACID, 2003).

Devido ao alto grau de homologia (>90\%) entre as isoformas de ras, assume-se habitualmente que elas são funcionalmente redundantes (PRIOR; HANCOCK, 2001). Sob condições normais, células quiescentes possuem menos de $5 \%$ de sua concentração de ras no estado ativo, contra quase $50 \%$ sob estimulação mitogênica (ADJEI, 2001). Sua atividade é regulada por meio da interconversão entre os estados ativo e inativo, e realizada por duas classes distintas de proteínas: os fatores de troca de nucleotídeos guanina (guanine nucleotide exchange factors - GEFs) e as proteínas ativadoras de GTPase (GTPase activating proteins - GAPs) (ALBERTS et al., 2004).

Os GEFs estimulam a dissociação do GDP e a ligação ao GTP do citosol, resultando na formação do estado GTP-ligante ativo. Diferentemente, os GAPs reconhecem a forma GTP-ligante e direcionam a atividade intrínseca de GTPase de ras, e isso aumenta a velocidade de hidrólise do GTP, e a inativa pela formação da proteína GDP-ligante (Figura 2) (REBOLLO; MARTÍNEZ, 1999; DUURSMA; AGAMI, 2003; ALBERTS et al., 2004). 


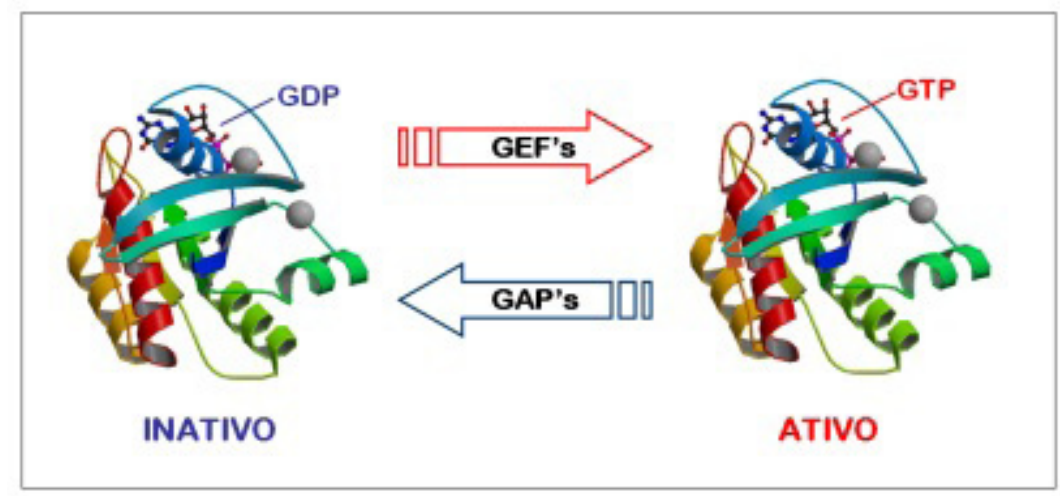

Figura 2. Regulação da atividade de ras pelo ciclo GTP-GDP. As proteínas GAPs inativam ras pela indução de hidrólise do GTP ligante, enquanto os GEFs a ativam, estimulando a dissociação do GDP. Fonte: adaptado de Alberts et al. (2004) e Protein Data Banking (2009).

Receptores de tirosino-quinase podem ativar ras pela ativação de um GEF, como a proteína sos, que estimula a conversão das formas GDP a GTP das proteínas ras (ALBERTS et al., 2004; CRESPO; LEÓN, 2000; DENAYER; RAVEL; LEGIUS, 2008). A ativação de um receptor de tirosino-quinase pode levarà ativação simultânea de várias vias de transdução de sinal (GRIFFITHS et al., 2002). Uma vez ativada, ras ativa várias outras proteínas sinalizadoras, e isso resulta na transmissão do sinal em diferentes vias. Uma delas é a cascata de fosforilação serina/treonina, que envolve a via MAPK (proteíno-quinase ativada por mitógeno) (ALBERTS et al., 2004). Quando ativada, a via MAPK estimula a proliferação celular e inibe a ocorrência de apoptose (AHLQUIST et al., 2008). Os três membros da família RAS exibem igual capacidade de ativação da via MAK e estímulo à proliferação celular (LEE et al., 2009).

Os membros da família de serina/treonina quinase raf são os efetores de ras melhor caracterizados. Esses efetores são responsáveis por regular a via MAPK. Dessa forma, as proteínas raf exercem papel fundamental na ação mitogênica de ras (ELLIS; CLARK, 2000; INDER; HANCOCK, 2008). A via ras-MAPK transporta sinais da superfície celular até o núcleo, alterando de forma significativa o padrão de expressão de genes que promovem a proliferação e diferenciação celular (ALBERTS et al., 2004; CHAN et al., 2004). A ativação da cascata MAPK é vital para a proliferação celular, e sua ativação aumentada contribui para o desenvolvimento do fenótipo transformado (SPANDIDOS et al., 2002).

\section{Oncogenes RAS}

\section{Aspectos moleculares}

As proteínas ras, componentes das vias de sinalização, são lideradas por receptores de membrana celular no controle da proliferação e na diferenciação ou morte celular, por isso elas têm uma grande importância na tumorigênese e na progressão tumoral em diversos tecidos (REBOLLO; MARTÍNEZ, 1999; MATSUO et al., 2004). Quando a função de ras é inibida ou inativada, a proliferação celular ou a diferenciação podem não ocorrer. De forma contrária, se a forma mutada de RAS for hiperativada, o efeito sobre a proliferação celular e diferenciação é acentuado, e pode resultar na formação de neoplasias malignas (ALBERTS et al., 2004).

Os genes RAS funcionam como "interruptores moleculares" em uma grande rede de vias de sinalização (SPANDIDOS et al., 2002). Mutações nos proto-oncogenes RAS têm sido detectadas em 20 a $30 \%$ de todos os tumores humanos (REUTER; MORGAN; BERGEMANN, 2000). Até o momento, os maiores índices de mutações de RAS foram detectados em adenocarcinomas do pâncreas (90\%), do cólon (50\%) e do pulmão (30\%) (SPANDIDOS 2007) 
As mutações são geralmente limitadas a um membro da família, dependendo do tipo celular transformado, uma vez que os níveis de RNAm dos genes RAS diferem em vários tipos celulares. Por exemplo, os níveis de RNAm de H-RAS são mais altos em pele e músculo, de K-RAS em intestino e timo, e de N-RAS em timo e testículos (DENHARDT, 1996; SPANDIDOS et al., 2002).

As oncoproteínas h-ras tem maior poder transformante em fibroblastos; n-ras são potentes indutores em células hematopoiéticas; e k-ras tem maior poder transformante em células epiteliais. Sabe-se ainda que n-ras tem a capacidade de suprimir a apoptose em linhagens celulares de mieloma múltiplo (ELLIS; CLARK, 2000). A seguir, sumarizamos na tabela 1 as freqüências de mutações em RAS detectadas em tumores de diferentes tecidos (SPANDIDOS et al., 2002; SPANDIDOS, 2007).

Tabela 1. Freqüência de mutações em RAS em tumores humanos.

\begin{tabular}{llc}
\hline Localização primária do tumor & Isoforma predominante de RAS & Freqüência de mutação (\%) \\
\hline Pâncreas & $\mathrm{K}$ & 90 \\
Tireóide & $\mathrm{H}, \mathrm{K}, \mathrm{N}$ & 60 \\
Cólon & $\mathrm{K}$ & 50 \\
Ovário & $\mathrm{K}$ & 45 \\
Pele & $\mathrm{H}, \mathrm{K}, \mathrm{N}$ & 45 \\
Síndrome mielodisplásica & $\mathrm{N}, \mathrm{K}$ & 40 \\
Endométrio & $\mathrm{K}$ & $10-40$ \\
Intestino delgado & $\mathrm{H}$ & 31 \\
Fígado & $\mathrm{N}$ & 30 \\
Leucemia Mielóide Aguda & $\mathrm{N}$ & 30 \\
Adenocarcinoma de pulmão & $\mathrm{K}$ & 30 \\
Cabeça e pescoço & $\mathrm{H}, \mathrm{K}$ & 30 \\
Bexiga & $\mathrm{H}, \mathrm{K}$ & 30 \\
Cérvice & $\mathrm{K}, \mathrm{H}$ & 30 \\
Cérebro & $\mathrm{N}, \mathrm{K}$ & 10 \\
Mama & $\mathrm{H}, \mathrm{K}$ & 10 \\
Rim & $\mathrm{H}$ & 30 \\
\hline
\end{tabular}

Fonte: Adaptado de SPANDIDOS et al. (2002) e SPANDIDOS (2007).

Poucos tumores exibem mutações nos três membros da família RAS. No câncer de pâncreas e de cólon são encontradas mutações exclusivamente em K-RAS. Em cânceres do trato urinário e bexiga, as mutações ocorrem primariamente no gene H-RAS, enquanto mutações em N-RAS são predominantes em tumores cerebrais e leucemias. De forma geral, as mutações ocorrem com mais freqüência em K-RAS e raramente em H-RAS (SPANDIDOS et al., 2002).

A prevalência de mutações em K-RAS em relação 
a H- e N-RAS sugere que o estímulo de K-RAS à formação neoplásica é mais intenso que dos demais genes desta família (LEE et al., 2009). Além disso, a maior frequencia de mutações em K-RAS nas neoplasias malignas de origem endodérmica como pâncreas, cólon e pulmão - sugere que a oncoproteína k-ras exerce atividade oncogênica ao nível de precursores da endoderme ou de células tronco (QUINLAN et al., 2008).

A ativação do proto-oncogene K-RAS ocorre por mutações de ponto que alteram a estrutura primária de p21 (COTTI et al., 2000; KUFE et al., 2003). Essas mutações acontecem freqüentemente nos códons 12 , 13, 59 e 61 (DUURSMA; AGAMI, 2003), mas são mais comuns no códon 12 - cerca de 90\% (COTTI et al., 2000). Em N-RAS, são mais freqüentes no códon 61 (REUTER; MORGAN; BERGMANN, 2000) e em H-RAS, no códon 12 (CONEJO et al, 1998; PANOV et al, 2004).
Essas mutações resultam geralmente em uma única substituição de aminoácido em p21, contudo, inibem a regulação dependente de GTPase. A transversão $\mathrm{GGC} \rightarrow \mathrm{GTC}$ no códon 12 de RAS causa a substituição do aminoácido glicina por valina, dando origem à oncoproteína freqüentemente encontrada em cânceres humanos de bexiga (Figura 3a) (GRIFFITHS et al., 2002).

Proteínas p21 mutantes têm menor interação com GAPs, e resultam em ligação permanente dessa ao GTP. Dessa forma, p21 permanece ativa mesmo na ausência de sinais de regulação, e mantem sinalização contínua para o núcleo e uma forte estimulação para a proliferação celular (Figura 3b) (COTTI et al., 2000; GRIFFITHS et al., 2002; KUBRUSLY et al., 2002). Mutações nesses códons acabam conferindo vantagem proliferativa às células (CORRADINI et al., 1993; KAMMOUNI et al., 2002; SPANDIDOS et al., 2002). a)

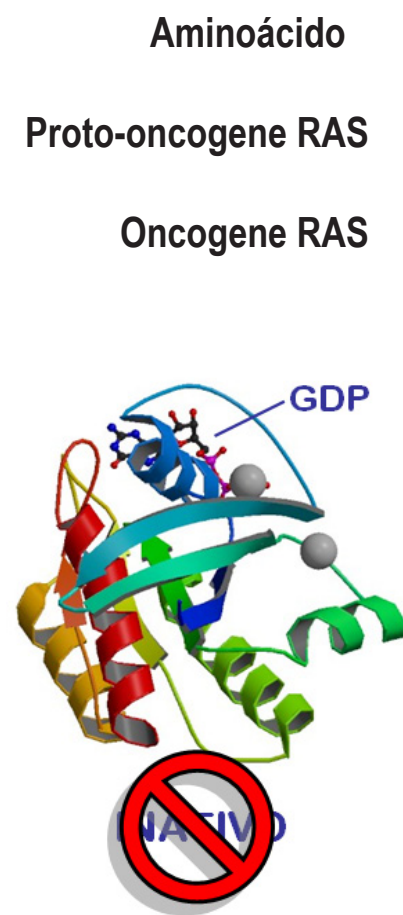

10

Gly Ala GGC GCC 12
Gly
GGC
V
GTC
Val b)
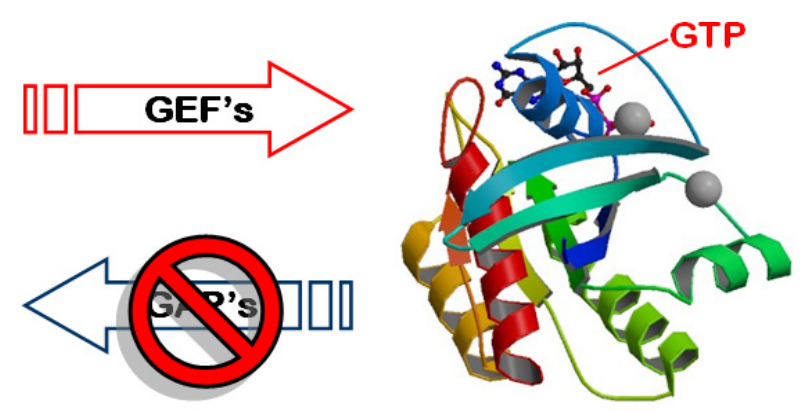

ATIVO

Figura 3. A oncoproteína ras. (a) Mutação mais freqüente: o oncogene difere do tipo selvagem por um único par de bases, codificando uma oncoproteína que difere do tipo selvagem em um único aminoácido, na posição 12 da matriz de leitura. (b) $\mathrm{O}$ efeito dessa mutação de ponto de sentido trocado é a oncoproteína ras não poder hidrolisar GTP, permanecendo no complexo ativo (ras-GTP). Fonte: Adaptado de Griffthis et al. (2002) e Protein Data Banking (2009). 
Além das mutações de ponto, a amplificação do gene também pode levar à indução neoplásica, tanto por aumentar a expressão de p21, quanto por propiciar o aparecimento de outras mutações devido à instabilidade genômica (MATSUO et al., 2004).

\section{Atividade biológica}

As oncoproteínas ras contribuem de forma significativa para a formação do fenótipo neoplásico maligno, que inclui descompasso entre a proliferação celular e apoptose, aquisição de capacidade invasiva e habilidade de neo-angiogenese (DENAYER; RAVEL; LEGIUS, 2008). Enquanto as formas selvagens de RAS inibem significantemente a proliferação celular e a formação de colônia, os alelos mutantes induzem fortemente esses eventos. Em algumas células, a expressão da forma selvagem deve ser significativamente mais alta que a mutante para inibir tais eventos, do contrário, é possível a transformação neoplásica pelo oncogene RAS mesmo na presença da forma selvagem (SPANDIDOS et al., 2002).

A eliminação da expressão do oncogene RAS por recombinação homóloga ou por RNA anti-senso tem demonstrado que sua expressão é necessária para manutenção do fenótipo neoplásico das células tumorais (REUTER; MORGAN; BERGMANN, 2000). Eventos como a super expressão ou amplificação do alelo mutante, ou ainda a perda do alelo selvagem, são necessários para promover um fenótipo maligno. Estudos de desequilíbrio alélico têm mostrado uma considerável perda de heterozigose no locus citogenético de K-RAS nos cânceres de mama, adenocarcinoma de pulmão, próstata, câncer pancreático e leucemia linfoblástica aguda. Contudo, a expressão do oncogene RAS induz a transformação apenas em conjunto com: (1) a ação de outro oncogene, como o MYC, por exemplo; ou (2) quando um gene supressor tumoral, como o P53, é inativado (SPANDIDOS et al., 2002).

Além de contribuir para a proliferação e transformação celular, a expressão dos oncogenes
RAS, em determinadas circunstâncias, pode levar a célula à senescência ou apoptose, por meio da ativação da proteína supressora tumoral p53 (SPANDIDOS et al., 2002; LEE et al., 2009). Quando expressos em fibroblastos não transformados, há elevação dos níveis de p53, p16 ou p21, resultando em senescência celular (SPANDIDOS et al., 2002). Para Lee et al. (2009), o oncogene K-RAS pode induzir fenótipo neoplásico mesmo na presença da forma selvagem de $\mathrm{p} 53$, enquanto os genes $\mathrm{H}-\mathrm{e}$ N-RAS apenas o fazem na ausência de p53 ativa.

As proteínas ras também estão envolvidas no processo de diferenciação celular, o que tem sido observado pela detecção de diferenciação de neoplasias em algumas malignidades humanas, portadoras de mutações nos genes H- ou K-RAS (SPANDIDOS et al., 2002).

\section{Particularidades em leucemias}

A ativação do oncogene RAS contribui para a proliferação celular e sobrevida de células progenitoras hematopoiéticas, e é freqüentemente observada em malignidades hematológicas como leucemias mielóides e múltiplos mielomas (CHAN et al., 2004). Estas mutações estão presentes em aproximadamente $40 \%$ dos pacientes com mielomas múltiplos recém-diagnosticados, aumentando a freqüência com a progressão da doença (REUTER; MORGAN; BERGMANN, 2000); em cerca de um terço das síndromes de mielodisplasias e leucemia mielóide aguda (LMA) (BOS, 1989; REUTER; MORGAN; BERGMANN, 2000), sendo mais freqüentes em N- e K-RAS (BOS, 1989); e já foram detectadas em leucemia mielomonocítica crônica e leucemia linfoblástica aguda (CHAN et al., 2004).

Aproximadamente $25 \%$ dos casos de leucemia mielóide apresentam mutação em N-RAS ou K-RAS, sendo extremamente raras em H-RAS (TYNER et al., 2009). Mutações em RAS estão presentes em 25-44\% das leucemias mielóides agudas (LMA), e caracterizam-se como uma 
das alterações genéticas mais comuns em LMA. Pacientes com LMA possuem mutações mais freqüentes em N-RAS (20-25\%) que em K-RAS (10-15\%). Mutações em N-RAS ocorrem quase exclusivamente em malignidades hematológicas, enquanto K-RAS e H-RAS apresentam mutações geralmente em tumores sólidos (CHAN et al., 2004).

Embora as mutações em RAS sejam raras em leucemia mielóide crônica (LMC), seu envolvimento tem sido demonstrado nas células bcr-abl+ pela presença de níveis aumentados de ras-GTP, que lidera a ativação dos efetores de ras (REUTER; MORGAN; BERGMANN, 2000). Apesar de ras não participar das cascatas de sinalização da proteína quimérica bcr/abl, sua atividade oncogênica situase no centro da via de sinalização mais proeminente na patogênese da LMC (FADERL et al., 1999). Nesse caso, os produtos do oncogene quimérico $\mathrm{BCR} / \mathrm{ABL}$ atuam nas vias de ras, modificando suas propriedades sinalizadoras. Através de uma cascata de eventos resultantes da fosforilação do produto de expressão do híbrido BCR/ABL, ativadores de ras-GTP são recrutados, e ativam permanentemente ras-GTP e disso resultam alterações na proliferação e diferenciação das células hematopoiéticas (SANTOS; FERREIRA, 2006).

\section{Considerações Finais}

A família proto-oncogênica RAS é formada pelos genes H-, N- e K-RAS. Sua atuação, em especial a do gene K-RAS, é conhecida e encontra-se hoje relativamente bem descrita. Fundamentalmente, seus produtos de expressão, denominados p21, realizam a transdução de sinal da membrana celular ao núcleo, e seu funcionamento se mostra vital ao desenvolvimento celular.

Mutações de ponto nesses genes - em sua maioria nos códons 12 em K- e H-RAS e 61 em N-RAS -, levam-nos à forma oncogênica. Esta passa a codificar uma proteína que se mantém permanentemente ligada à GTP. Isso resulta em sinalização ininterrupta, que funciona como forte estímulo à proliferação celular e induz o fenótipo neoplásico. É notável, portanto, a importância desses oncogenes na gênese do câncer.

Estudos da possibilidade de reversão da ligação permanente de p21 à GTP (o que poderia reverter o fenótipo neoplásico celular) fazem-se necessários e contribuiriam para a sobrevida de pacientes com mutação em genes da família RAS, em especial nos portadores de mutação em K-RAS, cujo potencial transformante é bastante elevado. Sua atuação, considerada agressiva, confere vantagem proliferativa às células e o torna alvo fundamental no estudo das neoplasias.

\section{Referências}

ADJEI, A. A. Blocking oncogenic ras signaling for cancer therapy. Journal of the National Cancer Institute, Bethesda, v. 93, n. 14, p. 1062-1074, 2001.

AHLQUIST, T.; BOTILLO, I.; DANIELSEN, S. A.; MELING, G. I.; ROGNUM, T. O.; LIND, G. E.; DALLAPICCOLA, B.; LOTHE, R. A. RAS signaling in colorectal carcinomas through alterations of RAS, RAF, NF1, and/or RASSF1A1. Neoplasia, Houston, v. 10, n. 7, p. 680-686, 2008.

ALBERTS, B.; BRAY, D.; LEWIS, J.; RAFF, M.; ROBERTS, K.; WATSON , J. D. Biologia molecular da célula. 4. ed. Porto Alegre: Artmed, 2004.

BAST, R. C.; KUFE, D. W.; POLLOCK, R.; WEICHSELBAUM, R. R.; HOLLAND, J. F.; FREI, E. Cancer medicine. 5. ed. Hamilton: BC Decker Inc, 2000.

BOS, J. L. Ras oncogenes in human cancer: a review. Cancer Research, Chicago, v. 49, n. 17, p. 4682-4689, 1989.

CHAN, I.. T.; KUTOB, J. L.; WILLIAMS, I. R.; COHEN, S.; KELLY, L.; SHINGEMATSU, H.; JOHNSON, L.; AKASHI, K.; TUVESON, D. A.; JACKS, T.; GILLILAND, D. G. Conditional expression of oncogenic K-ras from its endogenous promoter induces a myeloproliferative disease. The Journal of Clinical Investigation, New Haven, v. 113, n. 4, p. 528538, 2004.

CONEJO, J. R.; PARRA, T.; CANTERO, M.; JIMÉNEZ, A.; GRANIZO, V.; ARRIBA, G.; CARBALLO, F. Detection of H-ras mutations in urine sediments by a mutant-enriched PCR technique. Clinical Chemistry, Baltimore, v. 44, n. 7, p. 1570-1572, 1998. 
CORRADINI, P.; LADETTO, M.; VOENA, C.; PALUMBO, A.; INGHIRAMI, G.; KNOWLES, D. M.; BOCCADORO, M.; PIRELI, A. Mutational activation of $\mathrm{N}$ - and K-ras oncogenes in plasma cell dyscrasias. Blood, New York, v. 81, n. 10, p. 2708-2713, 1993.

COTTI, G. C. C.; SANTOS, F. P. S.; SEBASTIANES, F. M.; HABR-GAMA, A.; SEID, V.E.; MARTINO, R. B. Genética do câncer colorretal. Revista Médica, São Paulo, v. 79, n. 2/4, p. 45-64, 2000.

CRESPO, P.; LEÓN, J. Ras proteins in the control of the cell cycle and cell differentiation. CMLS, Cellular and Molecular Life Sciences, Basel, v. 57, n. 11, p. 16131636, 2000.

DEMIRAG, F.; ATALAY, E.; CRISS, W. E. Analysis of $\mathrm{K}$-Ras oncogene codon 12 mutations in a series of human lung cancers. Turkish Journal of Medical Sciences, Ankara, v. 30, n. 2, p. 129-134, 2000.

DENAYER, E.; RAVEL, T.; LEGIUS, E. Clinical and molecular aspects of RAS related disorders. Journal of Medical Genetics, London, v. 45, n. 11, p. 695-703, 2008.

DENHARDT, D. T. Signal-transducing protein phosphorylation cascades mediated by Ras/Rho proteins in the mammalian cell: the potential for multiplex signaling. Biochemical Journal, Londres, v. 318, n. 3, p. 729-747, 1996.

DUURSMA, A. M.; AGAMI, R. Ras interference as cancer therapy. Seminars in Cancer Biology, Philadelphia, v. 13, n. 4, p. 267-273, 2003.

EHRHARDT, A.; EHRHARDT, G. R.; GUO, X.; SCHRADER, J. W. Ras and relatives-job sharing and networking keep an old family together. Experimental Hematology, Copenhagen, v. 30, n. 10, p. 1089-1106, 2002.

ELLIS, C. A.; CLARK, G. The importance of being K-Ras. Cellular Signalling, Oxford, v. 12, n. 7, p. 425434, 2000.

FADERL, S.; TALPAZ, M.; ESTROV, V.; O'BRIEN, S.; KURZROCK, R.; KANTARJIAN, H. M. The biology of chronic myeloid leukemia. The New England Journal of Medicine, Boston, v. 341, n. 3, p. 164-172, 1999.

FOTIADOU, P. P.; TAKAHASHI, C.; RAJABI, H. N.; EWEN, M. E. Wild-type nras and kras perform distinct functions during transformation. Molecular and Cellular Biology, Washington, v. 27, n. 19, p. 6742-6755, 2007.

GOLBERT, L.; KOLLING, J. H.; LEITÃO, A. H.; POSSER, M.; LOBATO, R.; MAIA, A. L. Aumento da expressão do proto-oncogene ras no bócio multinodular: possível envolvimento na patogênese. Arquivos Brasileiros de Endocrinologia \& Metabologia, São
Paulo, v. 47, n. 6, p. 721-727, 2003.

GRIFFITHS, A. J. F.; MILLER, J. H.; SUZUKI, D. T.; LEWONTIN, R. C.; GELBART, W. M. Introdução à genética. 7. ed. Rio de Janeiro: Guanabara Koogan, 2002.

INDER, K.; HANCOCK, J. System output of the MAPK module is spatially regulated. Communicative \& Integrative Biology, Austin, v. 1, n. 2, p. 178-179, 2008.

KAMMOUNI, W.; RAMAKRISHNA, G.; SITHANANDAM, G.; SMITH, G. T.; FORNWALD, L. W.; MASUDA, A.; TAKAHASHI, T.; ANDERSON, L. $M$. Increased K-Ras protein and activity in mouse and human lung epithelial cells at confluence. Cell Growth \& Differentiation, Philadelphia, v. 13, n. 9, p. 441-448, 2002.

KIM, K.; LINDSTROM, M. J.; GOULD, M. N. Regions of $\mathrm{H}$ - and K-Ras that provide organ specificity/potency in mammary cancer induction. Cancer research, Chicago, v. 62 , n. 5, p. 1241-1245, 2002.

KUBRUSLY, M. S.; CUNHA, J E.; BACCHELLA, T.; ABDO, E. E.; JUKEMURA, J.; PENTEADO, S.; MORIOKA, C. Y.; SOUZA, L. J.; MACHADO, M. C. Detection of K-ras point mutation at codon 12 in pancreatic diseases: a study in a Brazilian casuistic. Journal of the Pancreas, Genova, v. 3, n. 5, p. 144-151, 2002.

KUFE, D. W.; POLLOCK, R. E.; WEICHSELBAUM, R. R.; BAST, R. C.; GANSLER,. T. S.; HOLLAND, J. F. Cancer Medicine. 6. ed. Hamilton: BC Decker Inc, 2003.

LEE, S.; LEE, S. J.; JUNG, Y. S.; XU, Y. B.; KANG, H. S.; HA, N. C.; PARK, B. J. Blocking of p53-snail binding, promoted by oncogenic K-Ras, recovers p53 expression and function. Neoplasia, Houston, v. 11, n. 1, p. 22-31, 2009.

MALUMBRES, M.; BARBACID, M. RAS oncogenes: the first 30 years. Nature Reviews - Cancer - Nature Plubishing Group, London, v. 3, n. 6, p. 7-13, 2003.

MATSUO, S. E.; MARTINS, L.; LEONI, S. G.; HAJJAR, D.; RICARTE-FILHO, J. C. M.; EBINA, K. N.; KIMURA, E. T. Marcadores biológicos de tumores tireoidianos. Arquivos Brasileiros de Endocrinologia \& Metabologia, São Paulo, v. 48, n. 1, p. 114-125, 2004.

NUSSBAUM, R. L.; McINNES, R. R.; WILLARD, H. F. Thompson \& Thompson - genética médica. 6. ed. Rio de Janeiro: Guanabara Koogan, 2003.

Thompson \& Thompson - genética médica. 7. ed. Rio de Janeiro: Elsevier, 2008.

OLIVEIRA, T. B.; CURY, P. M. Câncer de pulmão. Revista HB científica, São Jose do Rio Preto, v. 9, n. 1, p. 25-38, 2002. 
OLSON, M. F.; MARAIS, R. Ras protein signalling. Seminars in Immunology, Philadelphia, v. 12, n. 1 p. $63-$ 73, 2000.

PACHECO, F. A.; PASCHOAL, M. E. M.; CARVALHO, M. G. C. Marcadores tumorais no câncer de pulmão: um caminho para a terapia biológica. Jornal Brasileiro Pneumologia, Brasília, v. 28, n. 3, p. 143-149, 2002.

PANOV, S.; ROGANOVIC-ZAFIROVA, D.; STAVRIC, G.; YASHAR, G.; POPOV, Z. High frequency of the HRAS oncogene codon 12 mutation in Macedonian patients with urinary bladder cancer. Genetics and Molecular Biology, Ribeirão Preto, v. 27, n. 1, p. 9-14, 2004.

PHILIPS, M. R. Compartmentalized signalling of Ras. Biochemical Society Transactions, London, v. 33, n. 4, p. 657-661, 2005.

POCHYNYUK, O.; STOCKAND, J. D.; STARUSCHENKO, A. Ion channel regulation by ras, rho, and rab small gtpases. Experimental Biology and Medicine, Basel, v. 232, n. 10, p. 1258-1265, 2007.

PRIOR, I. A.; HANCOCK, J. F. Compartimentalization of Ras proteins. Journal of Cell Science, London, v. 114, n. 9 , p. 1603-1608, 2001.

PROTEIN DATA BANKING. Human K-Ras in complex with a GTP analogue. Disponível em: $<$ http://www.rcsb. org/pdb/explore.do?structureId=3GFT $>$ Acesso em: 22 out. 2009.

QUINLAN, M. P.; QUATELA, S. E.; PHILIPS, M. R.; SETTLEMAN, J. Activated kras, but not hras or nras, may initiate tumors of endodermal origin via stem cell expansion. Molecular and Cellular Biology, Washington, v. 28, n. 8, p. 2659-2674, 2008.

REBOLLO, A.; MARTÍNEZ, C. Ras proteins: recent advances and new functions. Blood, New York, v. 94, n. 9, p. 2971-2980, 1999.

REUTER, C. W. M.; MORGAN, M. A.; BERGMANN, L. Targeting the Ras signaling pathway: a rational, mechanism-based treatment for hematologic malignancies? Blood, New York, v. 96, n. 5, p. 16551669, 2000.

SANTOS, I. L.; FERREIRA, R. J. Aspectos biológicos, genéticos e moleculares do gene bcr-abl e sua relação com a leucemogênese. Arquivos de Ciências da Saúde da Unipar, Umuarama, v. 10, n. 1, p. 55-59, 2006.

SPANDIDOS, D. A. Oncogenes and tumor suppressor genes as paradigms in oncogenesis. Journal of BUON, Athens, v. 12, supl. 1, p. 9-12, 2007.

SPANDIDOS, D. A.; SOURVINOS, G.; TSATSANIS, C.; ZAFIROPOULOS, A. Normal ras genes: their onco- supressor and pro-apoptotic functions. International Journal of Oncology, Athens, v. 21, n. 2, p. 237-241, 2002.

TYNER, J. W.; ERICKSON, H.; DEININGER, M. W. N.; WILLIS, S. G.; EIDE, C. A.; LEVINE, R. L.; HEINRICH, M. C.; GATTERMANN, N.; GILLILAND, D. G.; DRUKER, B. J.; LORIAUX, M. M. Highthroughput sequencing screen reveals novel, transforming RAS mutations in myeloid leukemia patients. Blood, New York, v. 113, n. 8, p. 1749-1755, 2009.

Recebido em: 26 de maio de 2009

Aceito em: 13 de agosto de 2010 